\title{
BMJ Open Quantifying gender disparity in physician authorship among commentary articles in three high- impact medical journals: an observational study
}

\author{
Mira Mamtani (D) , ${ }^{1}$ Frances Shofer, ${ }^{2}$ Anita Mudan, ${ }^{2}$ Utsha Khatri, ${ }^{3}$ Rachael Walker, ${ }^{4}$ \\ Jeanmarie Perrone, ${ }^{2}$ Jaya Aysola ${ }^{5}$
}

To cite: Mamtani M, Shofer $F$, Mudan A, et al. Quantifying gender disparity in physician authorship among commentary articles in three highimpact medical journals: an observational study. BMJ Open 2020;10:e034056. doi:10.1136/ bmjopen-2019-034056

- Prepublication history for this paper is available online. To view these files, please visit the journal online (http://dx.doi. org/10.1136/bmjopen-2019034056).

Received 04 September 2019 Revised 25 November 2019 Accepted 08 January 2020

Check for updates

(c) Author(s) (or their employer(s)) 2020. Re-use permitted under CC BY-NC. No commercial re-use. See rights and permissions. Published by BMJ.

${ }^{1}$ Emergency Medicine, University of Pennsylvania, Philadelphia,

Pennsylvania, USA

${ }^{2}$ Emergency Medicine, University of Pennsylvania, Philadelphia,

Pennsylvania, USA

${ }^{3}$ Emergency Medicine, University of Pennsylvania, Philadelphia,

Pennsylvania, USA

${ }^{4}$ Temple University, Philadelphia,

Pennsylvania, USA

${ }^{5}$ Internal Medicine, University

of Pennsylvania, Philadelphia,

Pennsylvania, USA

Correspondence to

Dr Mira Mamtani;

mira.mamtani@pennmedicine. upenn.edu

\section{ABSTRACT}

Background Scholarship plays a direct role in career advancement, promotion and authoritative recognition, and women physicians remain under-represented as authors of original research articles.

Objective We sought to determine if women physician authors are similarly under-represented in commentary articles within high-impact journals.

Design/Setting/Participants In this observational study, we abstracted and analysed author information (gender and degree) and authorship position from commentary articles published in three high-impact journals between 1 January 2014 and 16 0ctober 2018.

Primary outcome measure Authorship rate of commentary articles over a 5 -year period by gender, degree, authorship position and journal.

Secondary outcome measures To compare the proportion of men and women physician authorship of commentaries relative to the proportion of men and women physician faculty within academic medicine; and to examine the gender concordance among the last and first authors in articles with more than one author.

Results Of the 2087 articles during the study period, $48 \%$ were men physician first authors compared with $17 \%$ women physician first authors $(p<0.0001)$. Of the 1477 articles with more than one author, similar distributions were found with regard to last authors: $55 \%$ were men physicians compared with only $12 \%$ women physicians $(p<0.0001)$. The proportion of women physician first authors increased over time; however, the proportion of women physician last authors remained stagnant. Women coauthored with women in the first and last authorship positions in $9 \%$ of articles. In contrast, women coauthored with men in the first and last author positions, respectively, in 55\% of articles.

Conclusions Women physician authors remain underrepresented in commentary articles compared with men physician authors in the first and last author positions. Women also coauthored commentaries with other women in far fewer numbers.

\section{INTRODUCTION}

Although women have achieved gender parity in medical schools on both sides of the

\section{Strengths and limitations of this study}

- A strength of our study includes the manual identification of inferred gender by first name and subsequent search of institutional websites and social media accounts for pictures and preferred pronouns, rather than reliance on internet gender identification programme.

- A limitation of our study is the lack of duplicate review of the inferred gender to provide additional validation of the results.

- Another limitation of this study, as well as all prior work in this area, is the use of binary gender and the inability to capture those potential authors who may identify as non-binary.

- Finally, we did not limit our authorship to those from US medical schools, and therefore the actual disparity between women physician authors and women US medical school physician faculty could be more or less pronounced.

Atlantic, ${ }^{1-3}$ they remain under-represented in academic medicine hierarchy, composing only $37 \%$ of associate professors and $25 \%$ of full professors. ${ }^{4}$ The lack of advancement of women in academic medicine becomes even more pronounced within leadership in academic medicine, with women currently representing only $18 \%$ of permanent medical school chairs and $19 \%$ of permanent medical school deans. ${ }^{56}$

Publications in medical journals play an integral role in the academic promotion process, impacting the transition from assistant to full professor. ${ }^{7}$ Prior work reveals that women remain under-represented as authors of original research articles in medical journals, and in some journals women representation has declined over time. ${ }^{8-10}$ Prior evidence from subspecialty journals found that women physicians authored fewer perspective-type 
pieces. ${ }^{11} 12$ Moreover, the editors at The Lancet recently commented on its journal's under-representation of women authors of commentary articles. ${ }^{13}$ Gender disparity in authorship among high-impact journals has far-reaching implications, given the importance of scholarship in career advancement, academic promotion and authoritative recognition. ${ }^{14}$ In fact, the Association of American Medical Colleges (AAMC), the American Medical Association and the American College of Physicians have all highlighted the importance of achieving gender equity in academic medicine. ${ }^{15-17}$

Commentary articles are a unique category that can be written by authors at any stage of their career and offer authors the ability to either contribute novel opinions on timely, relevant topics in healthcare or propose new directions for scientific enquiry. ${ }^{11}$ 18-22 These articles are distinct from editorials or invited commentaries, which by definition restrict the pool of possible authors. However, the lack of specificity on the process for selecting commentary pieces and thereby the subjective nature of accepting commentaries for publication may lend itself to implicit bias, potentially in favour of men over women. ${ }^{23-25}$ Prior studies have highlighted a disparity in authorship among men and women authors. ${ }^{9} 1026$ We chose to focus on men and women physician authors, as a disparity within physician authorship may contribute to the attrition of women physicians in academics. In addition the recently launched Time's Up Healthcare, a component of a nonprofit organisation Time's Up, highlights the need to better understand and address inequities that women experience in healthcare. ${ }^{27}$ Therefore, the primary objective of this study was to characterise recent trends in representation of women physician authorship of commentary articles within high-impact journals.

\section{METHODS}

We abstracted and analysed author information (gender, degree) and author position from New England Journal of Medicine (NEJM) Perspective, Journal of the American Medical Association (JAMA) Viewpoint, and Annals of Internal Medicine Ideas and Opinions articles published from 1 January 2014 to 16 October 2018. We selected these three top-ranked medical journals by InCites Journal Citation Report 2018 impact factor. ${ }^{28}$ We then searched the individual journal websites to extract articles during our study time period that were identified as one of the following: (1) JAMA Viewpoint, (2) NEJM Perspective and (3) Annals of Internal Medicine Ideas and Opinions. The gender of the author was determined by inspection of first name by a study team member. A separate study team member reviewed the data set for any missing data points. For the $20 \%$ of names that were androgynous or unfamiliar, we searched institutional websites, social media accounts such as LinkedIn, and internet search engines to find photographs or biographical paragraphs that included preferred pronouns such as he, she, her and him. ${ }^{3}{ }^{10}{ }^{29-32}$ We successfully identified gender in $100 \%$ of cases. Authors with degrees that included MD, DO or MBBS were counted as physicians. Authors with any other degree (eg, JD, PhD, MPH and so on) without MD, DO or MBBS degree were counted as non-physicians. We abstracted the first and last authorship position data, as those are often a proxy for research team involvement, with the first author often contributing the most as the mentee and the last author providing leadership to the team as the mentor. ${ }^{33-36}$ Given the first author position more consistently indicates a significant contribution to the manuscript compared with the last author position, our comparisons focused largely on the first author position. ${ }^{37}$ Articles with single authors were counted towards the first author position.

Our observational analysis had three main objectives. First, we described 5-year trends in authorship of commentary articles by gender, degree (MD/DO/ MBBS vs non-physician degree), authorship position and journal. Second, we compared the proportion of men and women physician authorship of commentaries relative to the proportion of men and women physician faculty within academic medicine. Lastly, among the subset of commentaries with more than one author, we examined the gender concordance among the last and first authors. The a priori rationale for this was to determine the role, if any, of gender concordance in the advancement of women physicians.

\section{Statistical analysis}

We calculated standard summary statistics (frequencies and percentages) for gender, first and last author positions, degree type, and journal. To determine changes in gender authorship over time, we used Cochran-Armitage test for trend, and Fisher's exact test to compare women with men authors by journal type. To compare the proportion of men and women physician first authors of commentary articles relative to the proportion of men and women physician faculty, respectively, in academic medicine, we used the AAMC as the comparison group, with the proportion of women physician faculty in academic medicine at $27 \%$ in $2014,28 \%$ in $2015,28 \%$ in $2016,28 \%$ in 2017 , and $29 \%$ in 2018 , and the proportion of men physician faculty in academic medicine at $50 \%$ in $2014,49 \%$ in $2015,51 \%$ in $2016,45 \%$ in 2017 , and $45 \%$ in $2018,{ }^{38}$ and performed Fisher's exact test for each year. We performed additional subgroup analyses to compare (1) the proportion of women physician first and last authors with the proportion of women physician full professors in academics, and (2) the proportion of women to men authors for which there was a single author. For the former, we used the AAMC as the comparison group, with the proportion of women physician full professors at $22 \%$ in 2018, and Fisher's exact test was used for both. Additionally, we calculated $95 \%$ CI on the difference of the two binomial proportions (women physician faculty and women physician first authors, as well as men physician faculty and men physician first authors) using standardised statistics and inverting two one-sided tests. 


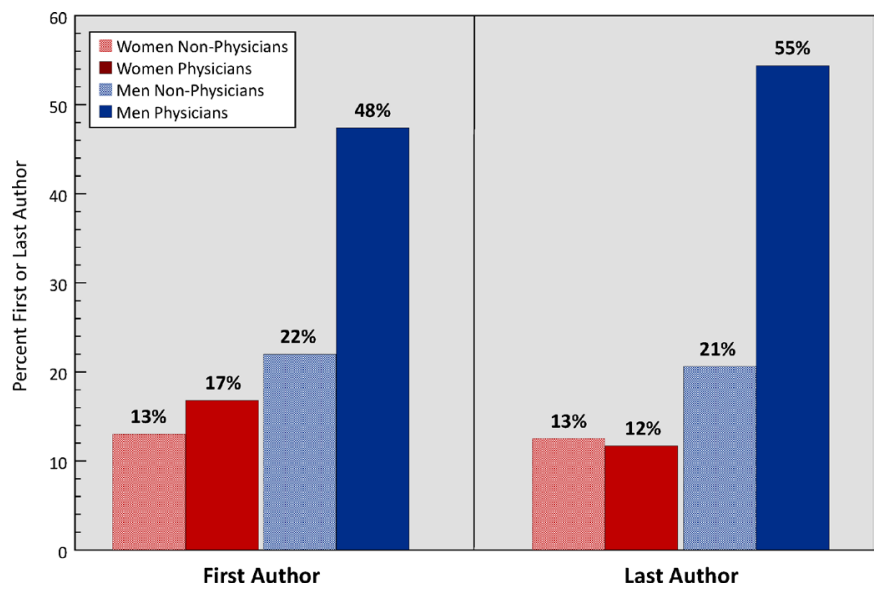

Figure 1 Authorship by position, gender and degree. The figure shows the total percentage of men and women authors in the first and last authorship positions by degree (MD/DO/ MBBS vs non-physician degree).

We calculated standard summary statistics to assess for gender concordance among the first and last author positions. Analyses were conducted using SAS V.9.4 statistical software and StatXact (V.11; Cytel Studio, Cambridge, Massachusetts). We followed the Strengthening the Reporting of Observational Studies in Epidemiology reporting guidelines for observational studies. ${ }^{39}$

\section{RESULTS}

Proportion of authors by gender, degree, authorship position and journal

Of the 2087 articles during the study period from 1 January 2014 to 16 October 2018, a total of 921 were JAMA Viewpoint, 910 were NEJM Perspective, and 256 were Annals of Internal Medicine Ideas and Opinions. Men and women accounted for $1457(70 \%)$ and $630(30 \%)$, respectively, in the first author position. Of all first authors, 994 (48\%) were men physicians compared with $355(17 \%)$ women physicians $(\mathrm{p}<0.0001)$. Of all physician first authors, $74 \%$ were men physicians compared with $26 \%$ women physicians. Of the 1477 articles with more than one author, similar distributions were found with regard to last authors: 1114 (75\%) and 363 (25\%) were men and women, respectively. Of all last authors, $807(55 \%)$ were men physicians compared with only 176 $(12 \%)$ women physicians $(\mathrm{p}<0.0001$; figure 1$)$.

men and women physicians in the first author position represent, respectively, $42 \%(\mathrm{n}=386)$ and $19 \%(\mathrm{n}=174)$ in NEJM, 52\% $(\mathrm{n}=477)$ and $13 \%(\mathrm{n}=124)$ in JAMA, and $51 \%$ $(\mathrm{n}=131)$ and $22 \%(\mathrm{n}=57)$ in Annals of Internal Medicine (table 1).

In those articles in which there was more than one author, men and women physicians in the last author position represent, respectively, $48 \%(\mathrm{n}=264)$ and $13 \%$ $(\mathrm{n}=72)$ in NEJM, 67\% $(\mathrm{n}=493)$ and $10 \%(\mathrm{n}=74)$ in JAMA, and $65 \%(\mathrm{n}=124)$ and $16 \%(\mathrm{n}=30)$ in Annals of Internal Medicine (table 2).

Finally, of those articles with only a single author, women and men represent $31 \% \quad(\mathrm{n}=189)$ and $69 \%$ $(n=421)$, respectively. Of all articles with a single physician author, women and men physicians represent $28 \%$ and $72 \%$, respectively.

\section{Proportion of women authors by journal}

When comparing the proportion of women first authors by journal type, JAMA (24\%, $\mathrm{n}=224)$ had the lowest proportion compared with either NEJM $(35 \%, \mathrm{n}=320)$ or Annals of Internal Medicine $(34 \%, \mathrm{n}=86)(\mathrm{p}<0.001)$. In

\begin{tabular}{|c|c|c|c|c|c|c|}
\hline & & 2014 & 2015 & 2016 & 2017 & 2018 \\
\hline Journal & First author position & n (\%) & n (\%) & n (\%) & $\mathrm{n}(\%)$ & n (\%) \\
\hline \multirow[t]{5}{*}{ AIM } & Women physicians & $10(21)$ & $6(13)$ & $12(23)$ & $12(24)$ & $17(28)$ \\
\hline & Women non-physicians & $6(13)$ & $5(11)$ & $9(17)$ & $5(10)$ & $4(7)$ \\
\hline & Men physicians & $26(54)$ & $27(59)$ & $23(44)$ & $23(46)$ & $32(53)$ \\
\hline & Men non-physicians & $6(13)$ & $8(17)$ & $8(15)$ & $10(20)$ & 7 (12) \\
\hline & Total articles & 48 & 46 & 52 & 50 & 60 \\
\hline \multirow[t]{5}{*}{ JAMA } & Women physicians & $20(12)$ & $27(13)$ & $23(12)$ & $27(14)$ & $27(18)$ \\
\hline & Women non-physicians & $16(9)$ & $18(8)$ & $19(10)$ & $26(13)$ & $21(14)$ \\
\hline & Men physicians & $94(54)$ & $107(50)$ & $108(58)$ & $99(51)$ & $69(45)$ \\
\hline & Men non-physicians & $43(25)$ & $64(30)$ & $35(19)$ & $41(21)$ & $37(24)$ \\
\hline & Total articles & 173 & 216 & 185 & 193 & 154 \\
\hline \multirow[t]{5}{*}{ NEJM } & Women physicians & $29(16)$ & $33(18)$ & $24(13)$ & $39(20)$ & $49(29)$ \\
\hline & Women non-physicians & $30(16)$ & $15(8)$ & $37(21)$ & $39(20)$ & $25(15)$ \\
\hline & Men physicians & $85(45)$ & $83(46)$ & $80(45)$ & 76 (39) & $62(37)$ \\
\hline & Men non-physicians & $43(23)$ & $49(27)$ & $38(21)$ & $42(21)$ & $32(19)$ \\
\hline & Total articles & 187 & 180 & 179 & 196 & 168 \\
\hline
\end{tabular}

AIM, Annals of Internal Medicine; JAMA, Journal of the American Medical Association; NEJM, New England Journal of Medicine. 
Table 2 Proportion of men and women last authors by degree, journal and year

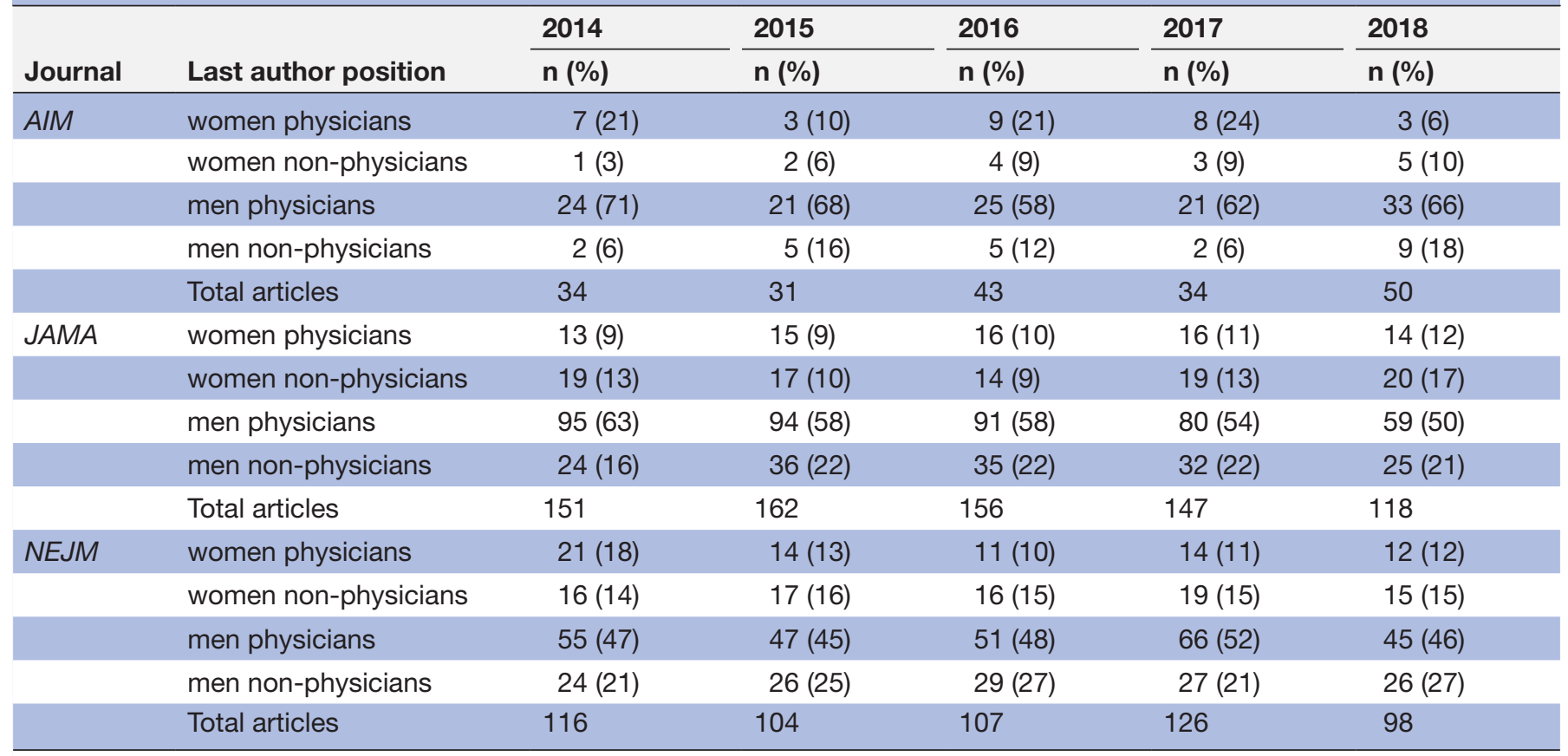

AIM, Annals of Internal Medicine; JAMA, Journal of the American Medical Association; NEJM, New England Journal of Medicine.

those articles in which there was more than one author, there was no significant difference in the proportion of women last authors by journal type: JAMA 22\% ( $\mathrm{n}=163)$, NEJM 28\% ( $\mathrm{n}=155)$ and Annals of Internal Medicine 23\% $(\mathrm{n}=45)(\mathrm{p}=0.049)$.

When comparing the proportion of women physician first authors by journal type, Annals of Internal Medicine had the highest proportion $(22 \%, \mathrm{n}=57)$, followed by NEJM $(19 \%, \mathrm{n}=174)$ and then JAMA $(13 \%, \mathrm{n}=124) \quad(\mathrm{p}<0.001)$. A similar distribution was found with the proportion of women physician last authors in those articles in which there was more than one author with Annals of Internal Medicine $(16 \%, \mathrm{n}=30)$, followed by NEJM $(13 \%, \mathrm{n}=72)$ and JAMA $(10 \%, \mathrm{n}=74)(\mathrm{p}<0.001)$.

\section{Proportion of authors by degree and authorship position over time}

From 2014 to 2018, the proportion of women authors in the first author position gradually increased (20142018: 27\% ( $\mathrm{n}=111), 24 \% \quad(\mathrm{n}=104), 30 \% \quad(\mathrm{n}=124), 34 \%$ $(\mathrm{n}=148)$ and $37 \%(\mathrm{n}=143)$, respectively, $\mathrm{p}<0.001)$. In contrast, there was no significant change in the ratio of women authors in the last author position over the same time period (2014-2018: 26\% ( $\mathrm{n}=77), 23 \% \quad(\mathrm{n}=68)$, $23 \%(\mathrm{n}=70), 26 \%(\mathrm{n}=79)$ and $26 \%(\mathrm{n}=69)$, respectively, $\mathrm{p}=0.67)$.

Similarly, when examining physician authors over time, the proportion of women physician first authors initially remained constant from 2014 to $2016 \quad(14 \% \quad(n=59)$, $15 \%(\mathrm{n}=66)$ and $14 \%(\mathrm{n}=59)$, respectively) and recently increased to $18 \%(\mathrm{n}=78)$ in 2017 and $24 \%(\mathrm{n}=93)$ in 2018 ( $<<0.001$; figure 2 ). In contrast, the ratio of women physician last authors did not significantly change between
2014 and $2018(14 \%(\mathrm{n}=41), 11 \%(\mathrm{n}=32), 12 \% \quad(\mathrm{n}=36)$, $12 \%(\mathrm{n}=38)$ and $11 \%(\mathrm{n}=29)$, respectively, $\mathrm{p}=0.53)$.

Proportion of women physician first authors to women physician faculty in academics

women physician first authors were under-represented compared with women physician faculty in academics from 2014 to 2017 . The proportion of women physician first authors was significantly lower than the proportion of women physician faculty in academics for years 2014-2017 (range of differences 8.6\%-15.5\%, $\mathrm{p}<0.001$; figure 3). However, in 2018, there was no significant

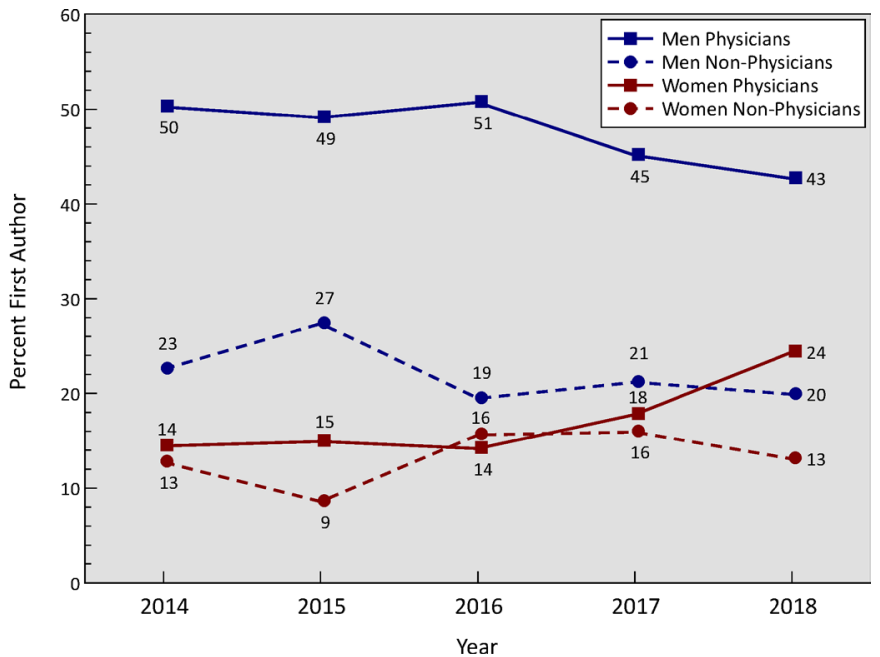

Figure 2 Per cent of first author by gender and degree over time. The figure shows the percentage of men and women first authors by degree (MD/DO/MBBS vs non-physician degree) over time from 2014 to 2018. 


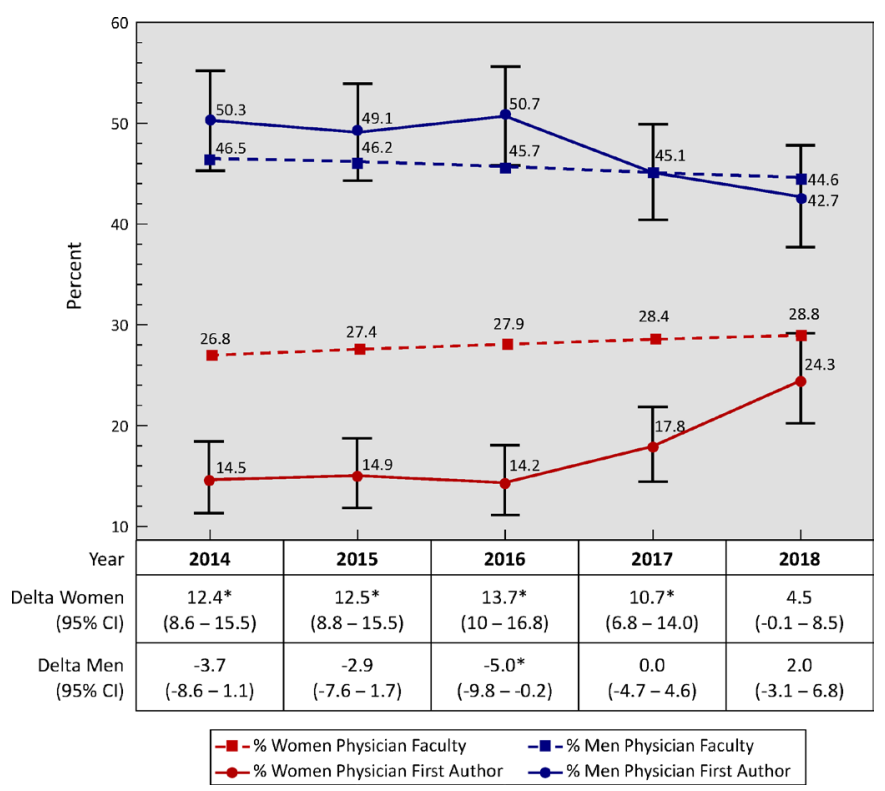

Figure 3 Proportion of men and women physician first authors and men and women physician faculty over time. The figure shows the proportion of men and women physician first authors relative to the proportion of men and women physician faculty, respectively, over time from 2014 to 2018. *Indicates a statistically significant difference.

difference between women physician faculty and women physician first authors $(4.5 \%, \mathrm{p}=0.054$; figure 3$)$.

\section{Proportion of men physician first authors to men physician faculty in academics}

In contrast, there was no significant difference between the proportion of men physician faculty and men physician first authors for 2014-2015 and 2017-2018 (range of differences $-3.7 \%$ to $2.0 \%, \mathrm{p}>0.05$ for all; figure 3 ). In 2016, the proportion of men physician first authors was significantly more $(5 \%)$ than the proportion of men physician faculty ( $\mathrm{p}=0.024$; figure 3 ).

\section{Proportion of women physician first and last authors to women physician full professors}

women physician first authors $(26 \%)$ were well represented compared with the proportion of women physician full professors in 2018 (22\%). The difference between the proportion of women physician full professors and women physician first authors was $4 \%$ (95\% CI $1.5 \%$ to $6.3 \%)$. In contrast, women physician last authors (18\%) were under-represented compared with the proportion of women physician full professors in academics in 2018. The difference between the proportion of women physician full professors and women physician last authors was $-4 \%(95 \%$ CI $-6.9 \%$ to $-2.0 \%)$.

\section{Gender concordance within the first and last author positions}

Of 1477 articles in which there was more than one author, women authors in the first and last positions were concordant in 132 (9\%) articles, and men authors in the first and last author positions were concordant in 805 (55\%) articles. In contrast, men last authors with women first authors accounted for 309 (21\%) articles, and women last authors with men first authors accounted for $231(16 \%)$ articles.

\section{DISCUSSION}

In three high-impact journals from 2014 to 2018, our analysis revealed that women physicians remain underrepresented in the first and last author positions $(17 \%$ and $12 \%$, respectively) compared with men physicians in the first and last author positions $(48 \%$ and $55 \%$, respectively). While the proportion of women physician authors in the first author position increased over time, the proportion of women physician authors in the last author position remained stagnant. In articles with multiple authors, the rates of women first authors were lowest when the last author was also a woman.

Prior studies have revealed a gender disparity in authorship of original research and editorial articles. ${ }^{8-10}$ Recent studies have also shown a gender gap in the authorship of perspective-type articles. ${ }^{1112}$ To our knowledge, this is the first study to examine the role of gender concordance among first and last authors in commentary pieces of high-impact general medicine journals. In addition, we build on prior work by comparing the rates of women physician commentary authorship with the proportion of women physician faculty annually. ${ }^{11}$

\section{Strengths and limitations}

Our study does have some key limitations. We inferred the gender of authors and did not rely on self-identification, which has the potential for misclassification. While we performed additional internet searches to identify names that were androgynous or unfamiliar in $20 \%$ of cases, we did not review pictures or biographical data for each name. In addition, we did not have a separate study team member perform a duplicate review of the data set to provide additional validation of the results. Another limitation of this study, as well as all prior work in this area, is the use of binary gender and the inability to capture those potential authors who may identify as non-binary. ${ }^{40}$ As medical journals accept submissions from outside of academia, including students, researchers and physicians from non-profit and private sectors, focusing on faculty in academia may, in fact, result in an underestimation of the gap. ${ }^{20-22}$ Finally, we did not limit our authorship to those from US medical schools, and therefore the actual disparity between women physician authors and women US medical school physician faculty could be more or less pronounced. A prior study, however, has found that this disparity persists even when limited to US medical school faculty. ${ }^{10}$ The strengths of our study include manual identification of gender by a study team member. Data derived from an online gender identification system, while easier to replicate and less resource-intensive, are unable to infer gender in a higher proportion of cases. ${ }^{19} 2641$

One potential reason for this authorship disparity is a lack of sufficient 'pipeline' or women in academia to author commentary articles. If commentaries are authored by women at any stage of their career, then our analysis reveals 
that women physician authors are under-represented compared with the proportion of women physician faculty in academic medicine from 2014 to $2017 .{ }^{40-22}$ As such, this is likely not a viable explanation for this authorship disparity. Alternatively, if primarily full professors in academia author commentaries, then our analysis reveals that women physician first authors are well represented compared with the proportion of women physician full professors in academia, but are under-represented in the last author position. While this may offer one explanation for the authorship disparity, commentary articles do not specify career stage to qualify for authorship, such that we cannot validate whether the gender disparity in commentary authorship mirrors the gender disparity of senior-level physicians. Moreover, a recent study has shown that gender disparities in commentary articles cannot be explained exclusively by seniority. ${ }^{19}$ Lastly, prior studies have shown that lack of sufficient pipeline is not generally a viable reason for gender disparities in academia. ${ }^{42}$

A second potential reason for the gender disparity in authorship rates is that women submit fewer manuscripts. We do not have access to the submission rates for the journals examined in this study; however, the multidisciplinary journal Science has reported that it receives a third fewer submission from women authors, compared with men authors, in the scientific fields they represent. ${ }^{44}$ While a higher proportion of submissions by women may improve the gender disparity in authorship, studies within other fields have shown that with similar types of submissions women still have lower manuscript acceptance rates compared with men. ${ }^{45}$ The current state of under-representation of women authors may also deter subsequent submissions by women. This concept of internalised bias, or 'imposter syndrome', has been shown to limit attempts or applications by women in other scenarios where gender parity is lacking. ${ }^{46}$

Another potential contributor to gender disparities in authorship of commentaries is institutional bias, defined as the "practices, scripts, or procedures that work to systematically give advantage to certain groups or agendas over others'. ${ }^{47}$ These biases are built into the fabric of the institution and can limit opportunities for certain groups of people, such as women. ${ }^{48}$ Prior literature reveals evidence of pervasive implicit bias and gender discrimination in academics, ${ }^{140-52}$ with subsequent limits in opportunities for recognition with publications, invited lectures, career advancement, promotion and leadership opportunities. ${ }^{53-55}$ These biases can also influence the journal's selection process for commentaries. Studies have shown that these biases can become more pronounced with less defined processes ${ }^{567}$ In contrast to original research articles, there is a less specific set of guidelines listed on journals' website to assess the merit or quality of a commentary piece. ${ }^{20-22}$ There may be instances in which submissions are encouraged or invited that are not readily apparent. We postulate that some of the differences seen in prior studies examining gender differences in authorship may be explained by differences in the selection process for commentary versus original research articles. For example, Ouyang $e t a t^{26}$ found that, in contrast to our study, there is a higher proportion of women first authors with women last authors in original research articles. ${ }^{26}$ This conflicting finding may be explained by more pronounced biases in the selection of commentary articles that favour authorship by men in the first and/or last position. Furthermore, these institutional biases have been shown to limit mentorship and sponsorship opportunities for women. ${ }^{5859}$ Patton $e t a l^{b^{0}}$ found men mentees receive greater sponsorship compared with women mentees from both men and women mentors, ${ }^{60}$ with women reporting difficulty in finding same-sex mentors. ${ }^{61}$ This could further explain why women last author mentors had the lowest proportion of women first author mentees.

Experts have called for better data collection in publishing as a key first step to understanding disparities in publishing. ${ }^{62}$ As more structured and objective processes have been shown to mitigate the effect of bias, ${ }^{57}$ tracking metrics related to invitation, submission and acceptance of commentary articles may highlight where efforts should be directed to achieve parity in authorship. Additional strategies may include implicit bias training for editors as well as academic mentors and sponsors. ${ }^{63}$ Mentors have an opportunity to be more deliberate in how sponsorship and other forms of micro-affirmations may be contributing towards gender disparities in career advancement in academia. ${ }^{53} 59$ As sponsorship that develops organically, rather than formally, can exclude talented individuals, formal institutional sponsorship programmes are integral to supporting women in medicine. ${ }^{64}$ Sponsors can both advocate for and assist women, including encouraging manuscript submissions to high-impact journals, applying for positions and overcoming aversion to selfpromotion. ${ }^{65}$ In addition, there is evidence that gendered associations of words in peer review exist and that the use of objective non-gendered language can promote gender equity in the selection process. ${ }^{66}$ For example, minimising the use of words that are implicitly associated with what are perceived to be traditionally masculine traits, such as replacing 'leadership opportunity' with 'opportunity to make a contribution', has shown to promote gender equity in grant funding. ${ }^{6768}$ Lastly, additional strategies described in the literature include achieving parity at the editor-inchief level within journals. ${ }^{69} 70$ Our study included a women editor-in-chief in one of three journals. While this disparity in journal leadership needs to be mitigated, interestingly, in our study, a women editor-in-chief did not necessarily translate into a more equitable inclusion of authors for commentary pieces. Parity within journal and institutional leadership may need to be coupled with objective selection processes, formalised institutional sponsorship opportunities, and the use of non-gendered terminology in the peer review process to promote submission and acceptance of women-authored manuscripts. 


\section{CONCLUSIONS}

Overall, our analysis reveals that women physicians are under-represented as authors in commentary articles. Experts recommend that a key first step in confronting this disparity include data collection on the extent of the gender disparity in authorship. The chasm among men and women authors in commentary pieces highlights the attenuation of the voice of women in academia, emphasising a need for greater efforts directed towards institutional support and sponsorship of these individuals. ${ }^{65}$ Any posited solutions to achieve parity in authorship must be a part of a larger strategic vision to ensure medical research reflects the contributions of a diverse body of physician scientists.

\section{Twitter Mira Mamtani @MiraMamtaniPenn}

Acknowledgements The authors wish to acknowledge FOCUS on Health \& Leadership for Women and the Center for Health Equity Advancement for their contributions to this manuscript.

Contributors MM and FS had full access to all the data in the study and take responsibility for the integrity of the data and accuracy of the data analysis. Concept and design: MM, JA, JP. Acquisition, analysis or interpretation of data: MM, JA, JP, AM, UK, RW, FS. Drafting of the manuscript: MM, JA. Critical revision of the manuscript for important intellectual content: MM, JA, JP, AM, UK, RW. Statistical analysis: FS. Supervision: JA, JP.

Funding The authors have not declared a specific grant for this research from any funding agency in the public, commercial or not-for-profit sectors.

Competing interests None declared.

Patient and public involvement statement It was not appropriate or possible to involve patients or the public in the design, conduct, reporting or dissemination of our research.

Patient consent for publication Not required.

Ethics approval Our institutional review board granted exempt status to this study. Provenance and peer review Not commissioned; externally peer reviewed.

Data availability statement Data are available in a public, open access repository. Extra data can be accessed via the Dryad Data Repository at http://datadryad.org/ (doi:10.5061/dryad.t6855h4).

Open access This is an open access article distributed in accordance with the Creative Commons Attribution Non Commercial (CC BY-NC 4.0) license, which permits others to distribute, remix, adapt, build upon this work non-commercially, and license their derivative works on different terms, provided the original work is properly cited, appropriate credit is given, any changes made indicated, and the use is non-commercial. See: http://creativecommons.org/licenses/by-nc/4.0/.

\section{ORCID iD}

Mira Mamtani http://orcid.org/0000-0002-5927-2532

\section{REFERENCES}

1 Association of American Medical Colleges. Us medical school applications and Matriculants by school, state of legal residence, and sex, 2017-2018, 2018. Available: http://www.aamc.org/download/ 321442/data/factstablea1.pdf [Accessed 1 Aug 2018].

2 Association of American Medical Colleges. Medical students, selected years, 1965-2013, 2019. Available: http://www.aamc.org/ download/411782/data/2014 table1.pdf [Accessed 10 Jul 2019].

3 Sidhu R, Rajashekhar P, Lavin VL, et al. The gender imbalance in academic medicine: a study of female authorship in the United Kingdom. J R Soc Med 2009;102:337-42.

4 Association of American Medical Colleges. US medical school faculty by sex and rank, 2018. Available: http://www.aamc.org/ download/495040/data/18table9.pdf [Accessed 5 Mar 2019].

5 The Association of American Medical Colleges. Trends: by department chair type and sex, 2018. Available: http://www.aamc.org/data/ facultyroster/305222/reportstsr.html [Accessed 9 May 2019].

6 The Association of American Medical Colleges. Trends: medical school deans by type and sex. Available: http://www.aamc.org/data/ facultyroster/305222/reportstsr.htm [Accessed 9 May 2019].
7 Blazey-Martin D, Carr PL, Terrin N, et al. Lower rates of promotion of generalists in academic medicine: a follow-up to the National faculty survey. J Gen Intern Med 2017;32:747-52.

8 Hart KL, Perlis RH. Trends in proportion of women as authors of medical Journal articles, 2008-2018. JAMA Intern Med 2019;179:1285.

9 Filardo G, da Graca B, Sass DM, et al. Trends and comparison of female first authorship in high impact medical journals: observational study (1994-2014). BMJ 2016;352:i847.

10 Jagsi R, Guancial EA, Worobey CC, et al. The "gender gap" in authorship of academic medical literature--a 35 -year perspective. $N$ Engl J Med 2006;355:281-7.

11 Silver JK, Poorman JA, Reilly JM, et al. Assessment of women physicians among authors of Perspective-Type articles published in high-impact pediatric journals. JAMA Netw Open 2018:1:e180802.

12 Larson AR, Poorman JA, Silver JK. Representation of women among physician authors of Perspective-Type articles in high-impact dermatology journals. JAMA Dermatol 2019;155:386.

13 Clark J, Zuccala E, Horton R. Women in science, medicine, and global health: call for papers. The Lancet 2017;390:2423-4.

14 Carr PL, Helitzer D, Freund K, et al. A summary report from the research partnership on women in science careers. $J$ Gen Intern Med 2019;34:356-62.

15 Butkus R, Serchen J, Moyer DV, et al. Achieving gender equity in physician compensation and career advancement: a position paper of the American College of physicians. Ann Intern Med 2018;168:721-3.

16 Reily KBO. AMA principles will further gender equity among physicians. Available: http://www.ama-assn.org/practicemanagement/physician-diversity/ama-principles-will-further-genderequity-among-physicians [Accessed 11 Dec 2019].

17 Kirch DG. Advancing women in academic medicine: progress, challenges, and hope for the future, 2019.

18 Berterö C. Guidelines for writing a commentary. Int J Qual Stud Health Well-being 2016;11:31390.

19 Thomas EG, Jayabalasingham B, Collins T, et al. Gender disparities in invited commentary authorship in 2459 medical journals. JAMA Netw Open 2019;2:e1913682.

20 New England Journal of Medicine. Information for authors, 2019. Available: http://www.nejm.org/doi/full/10.1056/ NEJM199201023260125 [Accessed 9 May 2019].

21 Annals of Internal Medicine. Information for authors, 2019. Available: https://annals.org/aim/pages/informationforauthors [Accessed 9 May 2019].

22 Journal of American Medical Association. Instruction for authors, 2019. Available: https://jamanetwork.com/journals/jama/pages/ instructions-for-authors [Accessed 9 May 2019].

23 Houston DA, Fazio RH. Biased processing as a function of attitude accessibility: making objective judgments subjectively. Soc Cogn 1989;7:51-66.

24 Manchikanti L, Kaye AD, Boswell MV, et al. Medical Journal peer review: process and bias. Pain Physician 2015;18:E1-14.

25 Gregory AT, Denniss AR. Everything you need to know about peer review - the good, the bad and the ugly. Heart, Lung and Circulation 2019;28:1148-53.

26 Ouyang D, Harrington RA, Rodriguez F. Association between female corresponding authors and female Co-Authors in top contemporary cardiovascular medicine journals. Circulation 2019;139:1127-9.

27 Times Up Healthcare, 2019. Available: https://http://www. timesuphealthcare.org [Accessed 3 May 2019].

28 InCites Journal Citation Report. Incites Journal citation report, 2019. Available: https://jcr.clarivate.com/JCRLandingPageAction.action [Accessed 15 Oct 2018].

29 Long MT, Leszczynski A, Thompson KD, et al. Female authorship in major academic gastroenterology journals: a look over 20 years. Gastrointest Endosc 2015;81:1440-7.

30 Bergeron JL, Wilken R, Miller ME, et al. Measurable progress in female authorship in otolaryngology. Otolaryngology-Head and Neck Surgery 2012;147:40-3.

31 Dotson B. Women as authors in the pharmacy literature: 1989-2009. Am J Health Syst Pharm 2011;68:1736-9.

32 Tinjum BE, Getto L, Tiedemann J, et al. Female authorship in emergency medicine parallels women practicing academic emergency medicine. J Emerg Med 2011;41:723-7.

33 Resnik DB, Master Z. Criteria for authorship in bioethics. Am J Bioeth 2011;11:17-21.

34 Baerlocher MO, Newton M, Gautam T, et al. The meaning of author order in medical research. J Investig Med 2007;55:174-80.

35 Tscharntke T, Hochberg ME, Rand TA, et al. Author sequence and credit for contributions in multiauthored publications. PLOS Biol 2007;5:e18. 
36 Wren JD, Kozak KZ, Johnson KR, et al. The write position. A survey of perceived contributions to papers based on byline position and number of authors. EMBO Rep 2007;8:988-91.

37 González-Alvarez JAuthor. Author gender in the Lancet journals. The Lancet 2018;391:2601.

38 Association of American Medical Colleges. Faculty roster benchmark reports, 2014 through 2018, 2018. Available: https://services.aamc. org/famous/ [Accessed 9 Jul 2019].

39 STROBE Statement. STROBE checklist for cohort, case-control, and cross-sectional studies (combined), 2007. Available: http://www. strobe-statement.org/index.php?id=available-checklists [Accessed 18 Oct 2018]

40 Frohard-Dourlent H, Dobson S, Clark BA, et al. "I would have preferred more options": accounting for non-binary youth in health research. Nurs Inq 2017;24:e12150.

41 Lerchenmüller C, Lerchenmueller MJ, Sorenson O. LongTerm analysis of sex differences in prestigious Authorships in cardiovascular research supported by the National Institutes of health. Circulation 2018;137:880-2.

42 Lillemoe KD. Surgical mentorship: a great tradition, but can we do better for the next generation? Ann Surg 2017;266:401-10.

43 Carnes M, Morrissey C, Geller SE. Women's health and women's leadership in academic medicine: hitting the same glass ceiling? $J$ Womens Health 2008;17:1453-62.

44 Berg J. Looking inward at gender issues. Science 2017;355:329.

45 Fox CW, Paine CET. Gender differences in peer review outcomes and manuscript impact at six journals of ecology and evolution. Ecol Evol 2019;9:3599-619.

46 Dancy TE, Brown MC. The mentoring and induction of educators of color: addressing the impostor syndrome in academe. J Sch Leadersh 2011;21:607-34.

47 Lucas J. Institutionalized bias. Encylopaedia Brittanica: Encyclopaedia Brittanica, Inc.

48 Hall WJ, Chapman MV, Lee KM, et al. Implicit racial/ethnic bias among health care professionals and its influence on health care outcomes: a systematic review. Am J Public Health 2015;105:e60-76.

49 Salles A, Awad M, Goldin L, et al. Estimating implicit and explicit gender bias among health care professionals and surgeons. JAMA Netw Open 2019;2:e196545.

50 Moss-Racusin CA, Dovidio JF, Brescoll VL, et al. Science faculty's subtle gender biases favor male students. Proc Natl Acad Sci U S A 2012;109:16474-9.

51 Rabinowitz LG. Recognizing blind spots - A remedy for gender bias in medicine? N Engl J Med 2018;378:2253-5.

52 Aakhus E, Mitra N, Lautenbach E, et al. Gender and Byline placement of Co-first authors in clinical and basic science journals with high impact factors. JAMA 2018;319:610-1.
53 Edmunds LD, Ovseiko PV, Shepperd S, et al. Why do women choose or reject careers in academic medicine? A narrative review of empirical evidence. The Lancet 2016;388:2948-58.

54 Jagsi R, Griffith KA, Jones R, et al. Sexual harassment and discrimination experiences of academic medical faculty. JAMA 2016;315:2120-1.

55 Kalaitzi S, Czabanowska K, Azzopardi-Muscat N, et al. Women, healthcare leadership and societal culture: a qualitative study. $J$ Healthc Leadersh 2019;11:43-59.

56 Heilman ME. Description and prescription: how gender stereotypes prevent women's ascent up the organizational ladder. J Soc Issues 2001;57:657-74.

57 Biernat M, Manis M. Shifting standards and stereotype-based judgments. J Pers Soc Psychol 1994;66:5-20.

58 Abramo G, D'Angelo CA, Murgia G. Gender differences in research collaboration. J Informetr 2013;7:811-22.

59 Aysola J, Barg FK, Martinez AB, et al. Perceptions of factors associated with inclusive work and learning environments in health care organizations: a qualitative narrative analysis. JAMA Netw Open 2018;1:e181003.

60 Patton EW, Griffith KA, Jones RD, et al. Differences in Mentor-Mentee sponsorship in male vs female recipients of national Institutes of health grants. JAMA Intern Med 2017;177:580-2.

61 Coe IR, Wiley R, Bekker L-G. Organisational best practices towards gender equality in science and medicine. The Lancet 2019;393:587-93.

62 Lundine J, Bourgeault IL, Clark J, et al. The gendered system of academic publishing. The Lancet 2018;391:1754-6.

63 Devine PG, Forscher PS, Cox WTL, et al. A gender bias habitbreaking intervention led to increased hiring of female faculty in STEMM departments. J Exp Soc Psychol 2017;73:211-5.

64 Gottlieb AS, Travis EL. Rationale and models for career advancement sponsorship in academic medicine: the time is here; the time is now. Acad Med 2018;93:1620-3.

65 Travis EL, Doty L, Helitzer DL. Sponsorship: a path to the academic medicine C-suite for women faculty? Acad Med 2013;88:1414-7.

66 Gaucher D, Friesen J, Kay AC. Evidence that gendered wording in job advertisements exists and sustains gender inequality. $J$ Pers Soc Psychol 2011;101:109-28.

67 Alvarez SNE, Jagsi R, Abbuhl SB, et al. Promoting gender equity in grant making: what can a funder do? The Lancet 2019;393:e9-11.

68 Magua W, Zhu X, Bhattacharya A et al. Are female applicants disadvantaged in National Institutes of health peer review? combining algorithmic text mining and qualitative methods to detect Evaluative differences in R01 reviewers' Critiques. J Womens Health 2017;26:560-70.

69 Ioannidou E, Rosania A. Under-Representation of women on dental Journal editorial boards. PLoS One 2015;10:e0116630.

70 Topaz CM, Sen S. Gender representation on Journal editorial boards in the mathematical sciences. PLoS One 2016:11:e0161357. 